\title{
Erratum to: Humanizing Digital Reality
}

Klaas De Rycke, Christoph Gengnagel, Olivier Baverel, Jane Burry, Caitlin Mueller, Minh Man Nguyen, Philippe Rahm, and Mette Ramsgaard Thomsen

\section{Erratum to:}

\section{K. De Rycke et al., Humanizing Digital Reality,} https://doi.org/10.1007/978-981-10-6611-5

In the original version of the book, the following belated corrections had been incorporated:

The author name "Mariana Popscu" has been changed to "Mariana Popescu" in Table of Contents, Contributors, Chapter 24 and Author Index.

The author name "Tom van Mele" has been changed to "Tom Van Mele" in Chapter 42.

In FM Acknowledgement, author names "Betty Pinks", "Adreas Kofler" and "Kombini" have been changed as "Bettina Pinks", "Andreas Kofler" and "Konbini", respectively.

In Back Cover, the term "Sixth" has been changed as "6th".

The updated original online version of this book can be found at https://doi.org/10.1007/978-98110-6611-5. 